\title{
Architecture and Human Senses
}

\author{
R.Ragavendira \\ School of Architecture and Interior Design \\ SRM University \\ Kattankulathur, Tamil Nadu - 603203
}

\begin{abstract}
Architecture, an important part of our environment, disturbs our experiences, feelings, memories, and ultimately the decisions we make. To explore the connection between architecture and the human Senses was the intention aimed at my paper. Whether positive or negative, everything created or done by man has an effect on his environment. Some people are more aware of their architectural environment some are less but at the end we all live with it and have at least an unconscious impression of it. We understand buildings through our senses. Although the five basic senses are often studied as individual systems covering visual, auditory, taste-smell, orientation and the haptic sensations, there is interplay between the senses.
\end{abstract}

Key Words: Architecture, Human Sense, Architectural environment, Thermal

\section{INTRODUCTION}

If the body had been easier to understand, nobody would have thought we had a mind[1].

- Richard Rorty (1979) The five senses felt by the eyes, ears, nose, mouth and skin. We understand buildings through our senses. The integration of senses using reason and logic. Rational thought expressed via self-awareness and intuition. The stores of experience in the long and short-term memories. Pure consciousness within the inner self; this also involves emotion [2].

The most important is sight, which gives us knowledge of three dimensions and colour.

Listening helps us to feel the building from a safe and relaxing point of view, so that we can sleep in comfort.

Touch is very important, as an architectonic feeling of each and every object is perceived by this sense, for example, a faucet in a bath that is smooth to the touch, a towel that is soft to the touch, or soap that is leathery to the touch. The sense of touch is the most intimate when buildings are considered.

Well, smell gives us a sense of cleanliness or dirtiness, of a turbid or rotten or fresh feel, and the ambience is felt first-hand with this sense.

Taste is not directly effective in buildings.

Thermal qualities - warm, cool, humid, airy, radiant, cosy - are an important part of our experience of a space, they not only influence what we choose to do there but also show how we feel about the space.

The light quality - direct, indirect, natural, artificial, diffuse, dappled, focused -can be subtly manipulated in the design of a space to achieve the desired effects [3].

- Heschong 1979

\section{ARCHITECTURE AND HUMAN SENSES}

All too often, architectural designs trust more heavily on the visual one. The other senses are unfortunately frequently neglected. This is unfortunate since it is through the senses that architecture can have profound effect. For instance, architectural building can more truly relate to the surrounding culture through all of the senses. Addressing historic, traditional or present-day cultural patterns can make a work of architecture a success when the senses are not ignored.

The architect must act as a composer that orchestrates space into synchronization for function and beauty through the senses - and how the human body engages space is of prime importance [4]. As the human body moves, sees, smells, touches, hears and even tastes within a space - the architecture comes to life.

The rhythm of architecture can be felt by occupants as a result of the architect's composition - or arrangement of all the sensorial qualities of space. By arranging spatial sensorial features, an architect can lead occupants through the functional and aesthetic rhythms of a created place. Architectural building for all the senses can serve to move occupants - elevating their experience.

Architectural space is about layering for all of the senses. Like a musical composition, spatial features come together into a symphony for occupants to experience. Bringing a space to life means that architectural function and form is not just primarily for the visual sense. By engaging all of the senses, form and function may be more fully expressed so occupants can have deeper, more meaningful moments - feeling the bouquet of their surroundings in all of its dimensions. 
An architect, who has internalized his trade, works in a similarly embodied manner; senses of success or failure are sensations of the body rather than products of cognitive knowledge. Sensation of bodily unbalance, deformation, irritation and pain inform me that the work on the drafting board has not arrived at a satisfactory resolution. This applies to writing, as well. One cannot intellectually analyse what is wrong, but our body knows. Our body also knows when the work has become a unified entity and projects this condition through a sensation of relaxed satisfaction and bodily pleasure [4].

The boundary line between the world and ourselves is identified by our senses. All the senses, including vision, are extensions of the tactile sense; the senses are specializations of skin tissue, and all sensory experiences are modes of touching, and thus related with tactility. Our contact with the world takes place at the boundary line of self through specialized parts of our enveloping membrane [5]. The view of Ashley Montagu, the anthropologist, based on medical evidence, confirms the primacy of the haptic realm (The skin) is the oldest and the most sensitive of our organs, our first medium of communication, and our most efficient protector. Even the transparent cornea of the eye is over lain by a layer of modified skin. Touch is the parent of our eyes, ears, nose, and mouth. It is the sense, which became differentiated into the others, a fact that seems to be recognized in the age-old evaluation of touch as 'the mother of the senses [6].

\section{ARCHITECTURE OF THE SENSES}

Various architectures can be distinguished on the basis of the sense modality they tend to emphasize. Alongside the prevailing architecture of the eye, there is a haptic architecture of the muscle and the skin. There is architecture that also recognizes the realms of hearing, smell and taste.

The architectures of Le Corbusier and Richard Meyer, for instance, cleverly favour sight, either as a frontal encounter, or the kinaesthetic eye of the promenade architectural (even if the later works of Le Corbusier incorporate strong tactile experiences in the forceful presence of materiality and weight). On the other hand, the architecture of the expressionist orientation, beginning with Erich Mendelsohn and Hans Scharoun, favors muscular and haptic plasticity as a consequence of the suppression of ocular perspectival dominance. Frank Lloyd Wright's and Alvar Aalto's architectures are based on a full recognition of the embodied human condition and of the multitude of instinctual reactions hidden in the human unconscious. In today's architecture, the multitude of sensory experiences in heightened in the work of Glenn Murcutt, Steven Holl and Peter Zumthor, for instance.

Alvar Aalto was consciously concerned with all the senses in the architecture. His comment on the sensory intentions in his furniture design clearly reveals this concern. Aalto's architecture exhibits a muscular and haptic presence. It incorporates dislocations, skew confrontations, irregularities and polyrhythms in order to arouse bodily, muscular and haptic experiences. His elaborate surface textures and details, crafted for the hand, invite the sense of touch and create an atmosphere of intimacy and warmth. Instead of the disembodied Cartesian idealism of the architecture of the eye, Aaltos architecture is based on sensory realism. His buildings are not based on a single dominant concept or gestalt; rather, they are sensory agglomerations. They sometimes even appear clumsy and unresolved as drawings, but they are conceived to be appreciated in their actual physical and spatial encounter, 'in the flesh' of the lived world, not as constructions of idealized vision. The eye is the organ of distance and separation, whereas touch is the sense of nearness, intimacy and affection.

\section{CONTROLLING HOW A ROOM FEELS}

Things like colour, lighting, interior element placement; integrated (horizontal or vertical) lines and even mirrors can have a huge impact on the size, proportion and mood of a space. Where specifics are explained about how to manipulate colour, style, lighting and mirrors into the design of a room to actually change its perceived qualities (Interior Design Optical Illusions).

It is interesting that such changes can alter interior spaces subtly or boldly, depending on how you design them into the space. Over time, occupants often want to change a room to accommodate new functional requirements. It is nice to know that there are ways to do this - "gain" square footage or "perceive" different moods.

With understanding into how the human visual system works, designers can create a great variety of different room feels. You will be able to truly achieve great effects (for both interior and exterior spaces) by combining your knowledge of perception with your knowledge of design.

\section{LIGHT CONCEPT}

The common space is the first place; which people pass when they enter the building in the morning. The place will always be the same but the time and moods of the people change during the day. Different colours in glass windows and skylights are aligned to the sun path and create different atmospheres inside the common area over 
the course of the day. The morning appears fresh blue. The noon hours bring very focused red spots of light, which can be used just for observation. And finally, the afternoon will have a soft yellow light, which ends day in a calm mood.

The ceiling grid also defines the skylight positions. The arrangement of the different colour skylights is in a random pattern but is always related to the sun path and the daytime-light colours concept. Therefore, the eastfacing skylight will have blue glass, the red glass panels belong to the south oriented skylight and the yellow glass is for the skylight facing the west. The different heights of the skylight structures create not only different light intensities inside the common room.
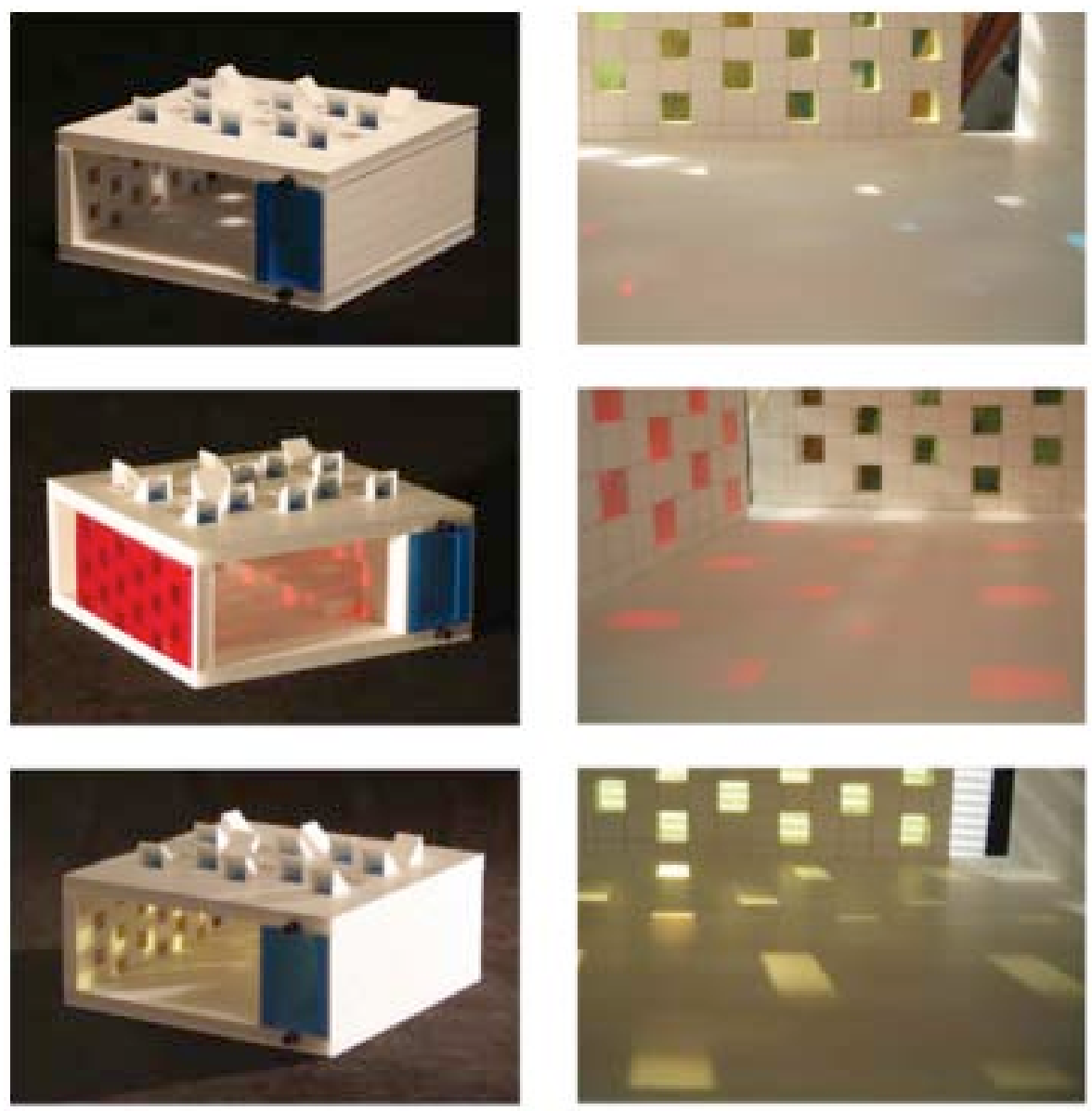

Figure 1: model showing the three different stages during the day - morning (blue light) - noon (red light) - afternoon (yellow light).

\section{MODELS USED WITH ARTIFICIAL AND SUNLIGHT HELPED TO STUDY THE LIGHT CONCEPT}

This model shows the three different stages during the day (Figure 1) - morning (blue light) - noon (red light) afternoon (yellow light). The colour glass windows will be arranged in a different order and number as shown in the model but the effect will be the same.

\section{THE SENSE OF SELF}

Paradoxically, the sense of self, strengthened by art and architecture, allows us to engage fully in the mental dimensions of dream, imagination and desire. In fact, we can focus our imagination and dreams only within the closed space of a room, not outdoors. Buildings and cities enable us to dream and imagine in safety, but they also provide a horizon for the understanding and experiencing of the human condition. Instead of merely creating objects of visual seduction, profound architecture relates, mediates and projects significance. It defines horizons of perception, feeling and meaning; our perceptions and experiences of the world are significantly altered by architecture. A natural phenomenon like a storm is a totally different condition when experienced through the device of architecture as compared to untamed nature. Thus architecture consists of acts, such as 
inhabiting, occupying, entering, departing, confronting, etc. rather than visual elements. The visual form of a window or a door, for instance, is not architecture; the acts of looking out through the window and passing through the door are genuine architectural encounters. The ultimate meaning of any significant building is beyond architecture itself; great buildings direct our consciousness back to the world. Profound architecture enables us to see the majesty of a mountain, the persistence and patience of a tree, and the smile on the face of a stranger. Architecture also directs our awareness to our own sense of self and being. It makes us experience ourselves as complete embodied and spiritual beings integrated with the flesh of the world. This is the great function of all art [7].

\section{NEEDS IN THE WORKPLACE}

I love the light in the room where I work and where things seem to change every day. The flowers are important. The room makes me want to work hard.

- Andrew O’Hagan

If you work and are spending one third to one half of your day in an office setting, then your surroundings there are as important as those in your home. Although we usually have little control over the buildings we work in, being aware of problems that can affect us will enable us to take counter-measures and may encourage the creation of stimulating and nurturing environments.

Over 80 per cent of staff in ordinary offices suffer from the classic sick building syndrome (SBS) symptoms of headache, tiredness, itchy and sore eyes, throat and skin, upper body pains, irritability and coughs, because all around magnetic fields, poor lighting, poor air quality, sound levels, poor design.

\begin{tabular}{|l|l|}
\hline Need & Achieved by \\
\hline Physiological & Good working conditions, attractive salary, subsidised housing, free catering \\
\hline Safety & Private health care, pension, safe-working conditions, job security. \\
\hline Social & $\begin{array}{l}\text { Good relationships, team spirit, company sports, office parties, informal } \\
\text { activities, open communication. }\end{array}$ \\
\hline Esteem & $\begin{array}{l}\text { Regular positive feedback, prestige job titles, write-up in company newssheets, } \\
\text { promotion and reward. }\end{array}$ \\
\hline Self- actualization & $\begin{array}{l}\text { Challenging job, discretion over work activity, promotion on opportunities, } \\
\text { encouraging creativity, autonomy and responsibility }\end{array}$ \\
\hline
\end{tabular}

Source: (CIBSE 1999, Huczynski 1991)

We live and work through our five senses and to thrive we need to use them. If they're blunted, we feel dissatisfied and creativity suffers. They suffered sensory deprivation and died of boredom. When this sort of deprivation occurs in the workplace, SBS symptoms result. They lower the immune system, so we succumb more readily to, say, a cold or flu. The solution is intelligent buildings; many offices are neither. Intelligent buildings need not be expensive. An igloo, for example, is very intelligent. Workplaces should be demand-led. They should be designed for the individuals using them [8].

Colours: Colour therapy has its roots in ancient Egypt. Scientific studies recognize that colours bring about emotional reactions to individuals. Our reactions and attitudes to colours differ from person to person. That colour affects us all is an undoubted fact. Its significance has been investigated and the results utilized in merchandizing, selling, home decorating, the workplace environment, industry, plant growth, nutrition, physics, physiology, psychology, ecclesiasticism and art. In fact, colour is so much a part of our lives that we tend to take it for granted. Colours that are useful in the office are: orange - stimulates creativity; yellow - intensifies the intellect and heightens motivation; red - energizes; blue - calming, fights physical and mental tension; green fights irritability and has a healing effect on the body. For the office, use colours that you are drawn to as these are the colours that will benefit your health. 
Music: Just about all offices have some type of music playing in the background. Music can affect emotional well-being, physical health, social functioning, communication abilities, and cognitive skills. Music in the workplace, either from piped-in music or from a radio, is sometimes used to mask sounds. Music can provide mental stimulation while performing monotonous tasks, which can help to reduce stress levels in the office. Some people, however, find music in the office intensely annoying, especially if it is too loud or inappropriate. I have found that soft, up-lifting music is very essential to the office "atmosphere". There is literally a mirage of good background music available on CD's. Search out the Internet on what is right for your office.

Lighting: Studies suggest that natural light increases human productivity and reduces fatigue and stress. By simply replacing your antiquated fluorescent tubes with full-spectrum tubes, you can instantly enhance your environment and your well-being! Full spectrum lighting emits a natural, balanced spectrum of light that is the closest you can get to sunlight indoors. Based on years of study not only do they bring out true, vibrant colours but they can also ease eye fatigue, improve your mood, reduce cortisol (stress hormone) levels, slow aging of the retina and reduce glare.

Make it smell good: Fresh flowers can be sweet smelling enough. But you can also choose to have air freshener in a can or spray. Scented candles are better alternatives, though. Besides the nice smell, scented candles promote warmth in the home office. An oil burner is also a natural way to make your office smelling good. Aromatic therapy is good for you, too. According to researchers, scents of lavender and citrus are the most soothing. These scents, along with lemon and jasmine, improve productivity also [10].

\section{CONCLUSION}

As the science of brain plasticity develops, architecture can make use of new findings and gadgets. The human senses basically collect data from stimuli (like light and sound) and feed it into our brain for assembly and interpretation. By arranging spatial sensorial features, an architect can lead occupants through the functional and aesthetic rhythms of a created place. Architectural building for all the senses can serve to move occupants elevating their experience.

\section{REFERENCES}

[1] Rorty, R. (1979) Philosophy and the mirror of nature, Princeton University press: New Jersy.

[2] Allwright, D., \& Bailey, K. M. (1991). Focus on the Language Classroom. New York: Cambridge University Press.

[3] Heschong, L. (1979). Thermal Delight in Architecture, The MIT Press Cambridge, London.

[4] Pallasmaa, J. (1996) The eyes of the skin: architecture and the senses, Academy Editions.

[5] Levin, M. D. (1993) Modernity and the Hegemony of Vision, University of California Press, Berkeley.

[6] Montagu, A. (1971) Touching: The Human Significance of the skin, Harper \& Row: New York.

[7] Pallasmaa, J. (2009) The thinking hand: existential and embodied wisdom in arcthitecture / Juhani Pallasmaa, Chichester, Wiley.

[8] Clements-Croome, D. (2000) Creating the productive workplace: edited by Derek Clements-Croome, E \& FN Spon: London.

[9] Pallasmaa, J. Touching the World - architecture, hapticity and the emancipation of the eye, Helsinki School of Architecture: FINLAND

[10] Lehman, L. M. (2009) Architectural Building for All the Senses: Bringing Space to Life [online], Available from http://sensingarchitecture.com/585/architectural-building-for-all-the-senses/, Accessed: 25-02-2011. 